Luis Ángel García Muñoz 


\section{Deleuze y el problema de la dialéctica hegeliana en Nietzsche}

\section{Introducción}

Deleuze, en el primer capítulo de Nietzsche y la Filosofía, ${ }^{1}$ introduce los recurrentes tópicos en las obras de Nietzsche: las relaciones entre fuerzas, y la voluntad de poder, con el objetivo de cuestionar la presencia de una dialéctica dentro del pensamiento nietzscheano.

Pasajes en la obra de Nietzsche, labradores de una interpretación cuestionable acerca de la confrontación de fuerzas - como el apartado "De la superación de sí mismo" en el Así habló Zaratustra ${ }^{2}$, donde se usan las palabras «órdenes», «seres obedientes», «juez»y «vengador», hacen que el estudio de Deleuze se dirija por los caminos de una aceptable duda, como lo haría cualquier estudioso minucioso.

Deleuze aborda este tema desde la perspectiva propia de un conocedor de Nietzsche como crítico de Hegel, tal como lo muestra la siguiente frase: «No entenderemos bien el conjunto de la obra de Nietzsche si no vemos "contra quién" van dirigidos los principales conceptos. Los temas hegelianos están presentes en esta obra como el enemigo que se combate». ${ }^{3}$ Lo anterior nos hace suponer que Deleuze, al haber realizado un estudio referente a la filosofía de Nietzsche, realizó un previo estudio de Hegel, por lo que su conocimiento de ambos autores no nos debe ser extraño. Pese a la previa afirmación, Deleuze se esfuerza por marcar las diferencias entre un autor $y$ otro, de manera explícita; de modo prudente afirma lo siguienteः «A lo largo de esta filosofía de la historia y de la religión [es decir, la obra de Nietzsche] no vamos a encontrar ninguna cita, ni siquiera ninguna caricatura de las concepciones de Hegel. La relación es más profunda, la diferencia es más profunda». ${ }^{4}$ Es por ello, por esta diferencia

1 G. Deleuze, Nietzsche y la Filosofía (trad. Carmen Artal), 6. ed., Barcelona, Anagrama.

2 F. Nietzsche, Asi Habló Zaratustra (trad. Andrés Sánchez Pascual), Madrid, Alianza, 1997.

3 Ibidem, p. 228.

4 Ibidem, p. 220. 
profunda, que un estudio y un análisis referente a la posibilidad de una dialéctica en Nietzsche no es una cuestión creada por una actitud propia del lector veloz e impaciente, sino un intento por hacer explícito lo profundo con la actitud paciente y minuciosa similar a la del artista vikingo y sus innumerables detalles.

Es en el apartado antes mencionado, de Así habló Zaratustra, donde encontramos una posible, mas no completa, relación corresponsal entre lo que parece una descripción del que obedece y del que se obedece a sí mismo con la analogía del señor y el siervo representativa del capítulo IV de la Fenomenología del Espíritu de Hegel: «Se le dan órdenes al que no sabe obedecerse a sí mismo». ${ }^{5}$

Esta posible-mas no completa- relación puede provocar en la interpretación del lector impaciente un efecto caracterizado por una relación entre autores. La analogía del señor y el siervo, en la Fenomenología del Espíritu, juega un papel de suma importancia como ilustración del método dialéctico hegeliano, por lo que su relación con los términos que designan a alguien que se obedece a sí mismo y a alguien que recibe órdenes de un tercero no puede ser perdida de vista por los lectores. De aquí que una interpretación acerca de la similitud entre métodos surja en el estudioso de los autores.

Un segundo evento que puede obstaculizar el logro de una interpretación de la infiltración activa de la dialéctica hegeliana en Nietzsche, es posible que surja de las contraposiciones entre comentadores e historiadores de ambos autores. Un ejemplo claro reside en la lectura de la Introducción a la historia de la filosofía de Xirau, donde se señala, en una nota al pie, que el método dialéctico de Hegel tiene «claros antecedentes» griegos, en especial de Heráclito, Platón y Aristóteles. ${ }^{6}$ En oposición a esta lectura, tenemos a Gadamer, quien afirma que la dialéctica en Hegel es una dialéctica propia, pero influenciada principalmente por la dialéctica eleática y platónica. ${ }^{7}$ Debido a interpretaciones parecidas a las del maestro Xirau, uno puede correr el riesgo de interpretar la dialéctica hegeliana como un efecto de la dialéctica perteneciente a Heráclito, no obstante, Gadamer excluye la influencia heracliteana; afirma que las influencias de $\mathrm{He}$ -

5 F. Nietzsche, Así Habló Zaratustra, p. 178.

6 R. Xirau, Introducción a la bistoria de la filosofía, 10 $0^{\mathrm{a}}$ reimp., $13^{\mathrm{a}}$ ed., México, UNAM, 2005, p. 338.

7 Cfr. H. G. Gadamer, La Dialéctica de Hegel: Cinco ensayos hermenéuticos (trad. Manuel Garrido), 7ª ed., Madrid, Cátedra: Teorema, 2007, pp. 11-13. 
gel son eleáticas y platónicas, haciendo referencia -en aquel primer capítulo perteneciente a Hegel y la dialéctica de los filósofos griegos-, a Parménides, Zenón, Aristóteles y a diversos diálogos platónicos sin mencionar a Heráclito. Lo anterior no se comenta para poner en duda el nivel de autoridad intelectual que gozan ambos comentadores e historiadores de Hegel, sino para mostrar un desacuerdo que en un inicio parece no tener importancia pero que puede traer consecuencias extraordinarias.

Nietzsche dice en La Genealogía de la moral lo siguiente:

Desde entonces [después de aquella modificación radical que sucumbió en la dolencia de la «mala conciencia»] el hombre cuenta entre las más inesperadas y apasionantes jugadas de suerte que juega el «gran niño» de Heráclito, llámese Zeus o Azar, -despierta un interés, una tensión, casi una certeza, como si con él se anunciase algo, se preparase algo, como si el hombre no fuera una meta, sino sólo un camino, un episodio intermedio, un puente, una gran promesa. ${ }^{8}$

Si Heráclito juega un papel en la obra de Nietzsche, al igual que en la obra de Hegel -según nos comenta Xirau-, diríamos que, efectivamente, existe una relación entre la dialéctica hegeliana y la de Nietzsche, usando a Heráclito como intermediario; pero si nos basamos en el comentario de Gadamer caracterizado por una exclusión de Heráclito en las influencias dialécticas, tendremos que entre Nietzsche y Hegel no hay relación tal que nos permita inferir que el primero usa la dialéctica del segundo.

Es por ello, entre otros sucesos, que las luchas entre fuerzas, ${ }^{9}$ así como el uso similar de las concepciones de siervo y señor -o el que se obedece a sí mismo con el que recibe órdenes-, y la polémica participación de Heráclito en ambos autores, llevan a plantearse la siguiente interrogante clamada por Deleuze: ¿Es «dialéctico» Nietzsche ${ }^{10} \mathrm{Y}$ más específicamente -aunado a las similitudes entre el apartado de la Fenomenología del Espiritu con aquellas concepciones nietzscheanas y

8 F. Nietzsche, La Genealogía de la Moral (trad. Andrés Sánchez Pascual), Madrid, Alianza, 2000, p. 110.

9 Descritas por Deleuze en el apartado designado a la voluntad de poder, en su obra Nietzsche y la filosofía.

10 G. Deleuze, op. cit., p. 17. 
la polémica participación de Heráclito en ambos autores-: ¿es «hegelianamente dialéctico» Nietzsche?

En el presente ensayo abordaremos, en un primer momento, la propuesta de Deleuze, la cual, de manera tajante, afirma que Nietzsche no retoma la dialéctica hegeliana, pues hay un criterio específico de diferencia entre el método hegeliano y el método nietzscheano, este último está englobado en lo negativo. Después se harán notar ciertas debilidades en la propuesta referida de Deleuze, intentando mostrar que sufre de un error notable. En un segundo momento, se aportarán otros criterios de diferencia que apuntan a señalar que el aspecto advertido por Deleuze no es el único que puede marcar la diferencia entre ambos autores con respecto a la dialéctica hegeliana.

\section{El papel de lo negativo en la relación entre Nietzsche y la dialéctica hegeliana en Deleuze: un criterio de diferencia}

En este apartado analizaremos el argumento de Deleuze para dar una respuesta negativa a la pregunta de si es 'hegelianamente dialéctico' Nietzsche.

Deleuze, desde el inicio de dicho análisis, acepta que, en Nietzsche, determinada fuerza entra en relación con otra fuerza dando inicio a un conflicto. Prueba de ello se puede encontrar en diversos pasajes de la obra de Nietzsche, donde frases como: «En todos los lugares donde encontré seres vivos encontré voluntad de poder; e incluso en la voluntad del que sirve encontré voluntad de ser señor ${ }^{11}$ o «exigir de la fortaleza que no sea un querer-dominar, un querer sojuzgar, un querer-enseñorearse [...] es tan absurdo como exigir de la debilidad que se exteriorice como fortaleza ${ }^{12}$ muestran un conflicto entre voluntades de poder que aspiran a más, a tal grado de simbolizar ese más con las diversas capacidades que el señor representa. Cabe resaltar que cuando el que sirve, es decir, el siervo, tiene la voluntad por ser señor, debe encontrar al que es señor actualmente, y propiciar un conflicto en el cual su voluntad exija el aumento y la excitación de las capacidades actuales. Estos conflictos, manifestados gracias a la

11 F. Nietzsche, Así habló Zaratustra, p. 176.

12 F. Nietzsche, La Genealogía de la Moral, p. 59. 
voluntad de poder, corresponden a aquellas relaciones entre fuerzas que nos describe Deleuze en un primer momento.

Estas relaciones de fuerzas -o estos conflictos- se podrían comparar de manera casi impulsiva con los conflictos que conlleva el proceso dialéctico en Hegel. Si ambos autores contienen tales similitudes, ¿̇en qué radica la diferencia que nos posibilita decir que Nietzsche no es un dialéctico hegeliano? Deleuze dice: «todo depende del papel de lo negativo en esta relación». ${ }^{13}$

Pareciera que Deleuze está pensando en el papel antitético en el proceso dialéctico en Hegel cuando habla de lo negativo. Cuando Deleuze expresa que «en Nietzsche la relación esencial de una fuerza con otra nunca se concibe como un elemento negativo de la esencia», ${ }^{14}$ alude a que el lector interprete que al estar contraponiendo el método nietzscheano con el hegeliano se nos diga que en el método de Hegel, es decir, en la dialéctica, el papel de lo negativo radique en que un elemento niegue la esencia del otro para así dar paso a un resultado o a lo que comúnmente se llama una sintesis. Parece que Deleuze le está dando un papel con engrandecida importancia a lo negativo dentro de la dialéctica hegeliana, ya que el mismo Hegel nos dice con respecto a su método:

$\mathrm{Al}$ principio motor del concepto [...] yo lo llamo dialéctica -en consecuencia, Dialéctica, no en el sentido de que ella disuelva, enrede $y$ lleve aqui y allá un objeto, un principio dado en general al sentimiento o a la conciencia inmediata y trate sólo con la deducción de su opuesto-, manera negativa tal como aparece frecuentemente, también, en Platón. Esta Dialéctica negativa puede considerar como su resultado último lo opuesto de una concepción, o decidida la contradicción misma; o también, pobremente, una aproximación a la verdad [...]. La más alta Dialéctica del concepto es producir y concebir la determinación -no como oposición y límite simplemente-, sino desde ella, comprender y producir el contenido y el resultado positivos, en cuanto con esto únicamente ella es, desarrollo $y$ progreso inmanente. ${ }^{15}$

13 G. Deleuze, op. cit., p. 17.

14 Idem.

15 G. W. F. Hegel, Filosofía del Derecho (trad. Juan Garzón Bates), México, UNAM, 1975, §31, p. 51; mi énfasis. 
En la anterior cita podemos ver que, efectivamente, el mismo Hegel adjetiva su Dialéctica como negativa, pero subraya que el progreso inmanente de la misma no sólo se basa en la deducción del opuesto de un concepto, y no depende sólo y únicamente de la oposición de un concepto para llegar a un resultado o síntesis positivo, sino que se vale de un progreso, de una determinación inmanente donde la oposición juega un papel relevante, mas no único y totalmente necesario.

Es de aquí, de una dialéctica negativa con factores de negación dentro de la misma, que Deleuze procede a marcar la distinción entre el método hegeliano con el nietzscheano, argumentando que en Nietzsche no existe esta negatividad característica en Hegel:

Nietzsche dice con razón que la fuerza tiene otra fuerza por objeto. Pero, precisamente, es con otras fuerzas que la fuerza entra en relación. Es con otra clase de vida que la vida entra en lucha. El pluralismo tiene a veces apariencias dialécticas; pero es su enemigo más encarnizado, su único enemigo profundo. Por ello debemos tomar en serio el carácter resueltamente antidialéctico de la filosofía de Nietzsche. ${ }^{16}$

En el fragmento citado, podemos ver de manera clara la posición de Deleuze respecto al tema que nos ha estado ocupando, así como la distinción que propone. En los conflictos -en la obra de Nietzsche- vemos fuerzas, seres vivos con voluntad de poder (como se hizo mención en la cita anterior de Así habló Zaratustra) que se relacionan entrando en un conflicto, siendo que esta relación que termina en conflicto, no requiere que una fuerza niegue a la otra, sino que ambas, siendo fuerzas y no contrarios, se relacionen, luchen.

El carácter negativo no existente en Nietzsche, y es esta ausencia, según Deleuze, lo que separa de manera radical el método nietzscheano del hegeliano. En el segundo, el proceso radica en que un factor se defina a través de otro como negativo para dar un resultado positivo, es decir, tenemos en un primer nivel el concepto A, para después deducir del mismo el concepto no-A y, así, en la confrontación basada en la negatividad de ambos, llegamos a un resultado positivo. Mientras que en Nietzsche, tendemos a un ser vivo con voluntad de poder $\mathrm{A}$ y a otro ser vivo con voluntad de poder $\mathrm{B}$, los cuales entran en conflicto y se relacionan sin contraponerse lógicamente.

16 G. Deleuze, op. cit., p. 17. 
Hasta este punto la respuesta de Deleuze a la pregunta de si Nietzsche es hegelianamente dialéctico radica en un no rotundo, argumentando, básicamente, que en Nietzsche, una fuerza que se relaciona con otra y que la hace obedecer, no la niega, no señala lo que no es, sino que afirma su propia diferencia y goza de esta diferencia. ${ }^{17}$

Obviamente, al mencionar la palabra diferencia y no negación, Deleuze está pensando en el pathos de la distancia tratado por Nietzsche y abordado como característica del superior o de la nobleza anterior a la revalorización que es tema en aquel primer tratado de $L a$ Genealogía de la Moral. ${ }^{18}$ Donde este pathos de la distancia logra que en lugar de negar otra fuerza, simplemente se marque una diferencia haciendo que la primera se afirme por sí misma y no por medio de la otra. Es decir, es muy diferente que $X$ se afirme como $X$ a que se afirme como no-Y. En la dialéctica hegeliana, el concepto deducido de otro concepto de un modo similar al de no-Y marca la negatividad de la que nos viene hablando Deleuze, la cual, según él, no se encuentra en Nietzsche.

Hasta este momento, parece que Deleuze olvidó el otro pathos mencionado por Nietzsche: el pathos reactivo, ${ }^{19}$ el cual se distingue por medio del otro. El pathos reactivo, como su nombre lo indica, reacciona a una determinada acción, es decir, no es sino por el otro - por aquel que se afirma a sí mismo-, que éste cobra relevancia. Este pathos reactivo, al depender de una primera variable que se afirma a sí misma, se distingue a través del otro como un no-X, haciendo de este pathos algo característico de la negatividad.

Deleuze, al hablar de las relaciones con otras fuerzas, se refiere a fuerzas caracterizadas por el pathos de la distancia, donde lo negativo es omitido en estas relaciones y, por lo tanto, en las relaciones referidas por Deleuze, se omiten las fuerzas con carácter negativo propias del pathos reactivo.

Sería un tanto ingenuo suponer que Deleuze omitió de manera intencional el asunto del pathos reactivo en Nietzsche para, así, tajar de manera forzada la diferencia entre los métodos de ambos autores con el producto de una omisión intencionada. Deleuze no omite el tema de la negación dentro de las fuerzas inferiores - de borrego, o esclavo en la obra de Nietzsche-, sino que lo mitiga de tal manera que

${ }^{17}$ Cfr. Idem.p. 17.

${ }^{18}$ Cfr. F. Nietzsche, La Genealogía de la Moral, pp. 37-38.

19 Cfr. Ibidem, p. 97. 
logra poner como criterio principal de diferencia entre los autores, lo negativo, a la vez que acepta en ambos la presencia de este factor.

Esto podría sonar extraño, ya que al poner como criterio lo negativo, es decir, al afirmar que Nietzsche es antidialéctico y que en las relaciones que él anuncia entre fuerzas no se concibe nada como negativo de una esencia, ${ }^{20}$ nos dice que la diferencia entre ambos autores con respecto a la dialéctica es que en uno no la hay, mientras que en el otro sí: «El "sí" de Nietzsche se opone al "no" dialéctico; la afirmación a la negación dialéctica; la diferencia a la contradicción dialéctica». ${ }^{21}$ Pero, como hicimos mención en párrafos arriba, en Nietzsche sí hay un factor negativo, el cual reside en las fuerzas de pathos reactivo. Nietzsche dice, refiriéndose a los pathos reactivos, que éstos se designan sencillamente en contraposición al noble, ${ }^{22}$ esto es, a partir de él.

¿Cómo, entonces, Deleuze logró mitigar la presencia de este factor negativo en la obra de Nietzsche, logrando que, aun existiendo una presencia de este factor, la diferencia entre ambos autores tratados radique en un solo criterio que designe que en uno lo negativo juega un papel y en el otro no? Muy fácil: Deleuze asigna la visión dialéctica a una sola visión, únicamente a la del esclavo y no a la del señor.

Deleuze, en efecto, no omite de manera exterminante lo negativo en Nietzsche, pues incluso él acepta la existencia de fuerzas designadas así por medio de otras fuerzas diciendo: «sólo una fuerza [...] niega todo lo que ella no es y hace de esta negación su propia esencia y el principio de su existencia». ${ }^{23}$

Esta fuerza designada por Deleuze, al estar bañada del factor de lo negativo en la obra de Nietzsche, puede relacionarse con la dialéctica hegeliana, permitiendo afirmar lo siguiente:

Por eso Nietzsche presenta la dialéctica como la especulación de la plebe, como el modo de pensar del esclavo. [...] la relación del señor y el esclavo no es, en sí misma, dialéctica.

\footnotetext{
Cfr. G. Deleuze, op. cit, p. 17.

Ibidem, p. 18.

22 Cfr. F. Nietzsche, La Genealogía de la Moral, p. 40.

23 G. Deleuze, op. cit., p. 18. 
¿Quién es dialéctico, quién dialectaliza la relación? Es el esclavo, el punto de vista del esclavo, el pensamiento desde el punto de vista del esclavo. ${ }^{24}$

Con lo anterior podríamos interpretar que Deleuze responde a la pregunta de si es hegelianamente dialéctico Nietzsche, con un no; argumentando que no hay algún factor negativo en el método nietzscheano y, que, a la vez, el único factor negativo que se pudiera presentar sería en la sola visión del esclavo. Lo anterior no nos responde con plena satisfacción. Ya que siendo lo negativo el criterio único de diferencia entre ambos autores para Deleuze, es sumamente extraño que acepte la presencia de lo negativo tanto en Nietzsche como en Hegel.

$\mathrm{El}$ hecho de que el factor negativo, impulsor de una posible relación con la dialéctica hegeliana, se presente en la sola visión del esclavo, no implica que lo negativo esté fuera de la obra de Nietzsche, pues eso supondría un carácter dogmático, en mencionado autor, el cual se orientaría al rechazo y al exterminio del esclavo mismo.

Deleuze, al creer que la dialéctica hegeliana se basa en una necesaria contradicción, y aceptando que la fuerza del esclavo, o el pathos reactivo, se basa en una negación por deducción de un concepto que se afirma a sí mismo, afirma que el señor y el siervo, dentro del panorama hegeliano, ocupan una misma jerarquía nivelada con el siervo o esclavo nietzscheano.

Si la dialéctica propiciada por lo negativo se encuentra sólo y exclusivamente en el esclavo, tendríamos que el señor y el siervo hegelianos son esclavos nietzscheanos en el sentido de que gozan de un carácter negativo.

Mas aún con lo anterior, no se concibe el porqué Deleuze extirpa la negatividad del esclavo en la obra de Nietzsche, otorgando este criterio de distinción que menciona.

Debido a ello, el criterio único, propio de lo negativo, no es el criterio adecuado para distinguir a Hegel de Nietzsche y viceversa. El hecho de que ambos participen de este carácter negativo y de que el criterio anunciado por Deleuze radique en que en uno no hay negatividad mientras que en el otro sí, nos obliga a pensar que lo señalado por Deleuze no goza de una total validez.

Ahora bien, si no estando conformes con lo anteriormente expuesto en este apartado, se manifiesta que el criterio mencionado por

24 Ibidem, p. 19. 
Deleuze con respecto a lo negativo no radica en que en uno sí lo hay mientras que en otro no, sino que en ambos lo hay pero con una diferente función, con un diferente papel, respondería que en sentencias previamente mostradas propias de Deleuze como: «en Nietzsche la relación esencial de una fuerza con otra nunca se concibe como un elemento negativo de la esencia» y "el "sí" de Nietzsche se opone al "no" dialéctico; la afirmación a la negación dialéctica; la diferencia a la contradicción dialéctica ${ }^{25}$ existe cierta ambigüedad que propicia diversas trabas en el trabajo del mencionado autor.

Siguiendo la línea propia a un criterio ambiguo o no válido, me propongo mostrar otros criterios de distinción entre los autores que sucumbirían al proceso analizado.

\section{I.I Lo negativo en Nietzsche y el asunto del reconocimiento mutuo}

Como apreciamos en el apartado precedente, Deleuze se esforzó en mitigar la presencia de lo negativo en la obra de Nietzsche. Pero al sólo mencionar lo negativo del esclavo de manera dulcificada, evidenció otros factores que designan un brote de lo negativo en Nietzsche.

En La Genealogía de la Moral podemos ver que Nietzche habla de antítesis incluso cuando ésta forma parte de un progreso dialéctico, incluso tomando en cuenta que Deleuze afirma un carácter resueltamente antidialéctico en la filosofía de Nietzsche. ${ }^{26}$

La sentencia en cuestión es la siguiente:

El pathos de la nobleza y la distancia, como hemos dicho, el duradero y dominante sentimiento global y radical de una especie superior dominadora en su relación con una especie inferior, con un «abajo»-éste es el origen de la antítesis «bueno»y «malo». ${ }^{27}$

Lo anterior no prueba una dialéctica en Nietzsche, sino el carácter de lo negativo en el autor, el cual fue sosegado por su comentador Deleuze.

Y este carácter de lo negativo en la obra de Nietzsche, sosegado por Deleuze, sigue brotando en deducciones como la relacionada con Heráclito. En un inicio, mencionamos una sentencia en la que

25 Ibidem, pp. 17-18.

${ }^{26}$ Cfr. Ibid., p. 17.

27 F. Nietzsche, La Genealogía de la Moral, p. 38.

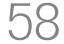


Nietzsche hace alusión al azar heracliteano. Si este azar toma un papel relevante en la obra de Nietzsche, y Heráclito es considerado por algunos comentadores como realizador de un esbozo propio de una lógica antagónica por las frecuentes manifestaciones de parejas de contrarios en sus fragmentos, ${ }^{28}$ tendríamos que al mostrar factores antagónicos basados en la negatividad deducida de un factor primero, sería común en la obra de Nietzsche, rescatando así otro carácter de negatividad en el autor.

Teniendo estos eventos en los que lo negativo se subraya en el autor, parece extraño que, para Deleuze, la presencia de estos eventos juegue el papel decisivo en cuanto al tema de la dialéctica hegeliana en Nietzsche. Por lo que una vez más, el lector presuroso encontrará trabas e inseguridades en lo descrito por Deleuze.

Pese a las anteriores debilidades del comentador, las cuales se han reducido a su mitigación del papel de lo negativo en Nietzsche y la persistencia de una ambigüedad en el criterio designado por él para diferenciar a Hegel y a Nietzsche en torno a la dialéctica, su aportación, respecto a que la dialéctica sólo se encuentra en la visión del esclavo en Nietzsche, es sumamente interesante.

Parece que el criterio elegido por Deleuze, es decir, lo negativo, no es el adecuado debido a las debilidades mencionadas. Por ello, basándonos en la argumentación de Deleuze expondremos lo que pareciera ser un criterio, no único, pero más adecuado que el de lo negativo.

Deleuze acepta que la dialéctica se podría encontrar sólo en el esclavo debido a que éste se determina basándose en el otro, en el señor y noble que goza de un pathos de distancia y no reactivo.

Deleuze hace, después de lo anterior, una comparación con el señor y el siervo que menciona Hegel y los coloca en un mismo nivel, en la misma jerarquía del esclavo mencionado en Nietzsche:

Si la relación de señor y esclavo adopta fácilmente la forma dialéctica, hasta el punto de haberse convertido en un arquetipo o en una figura escolar para cualquier joven hegeliano, es porque el retrato del señor que nos presenta Hegel es, desde el inicio, un

${ }^{28}$ Cfr. C. Ramnoux, "Los presocráticos", en Historia de la filosofía: La filosofía griega, vol. 2, Parain Brice (director), (trad. Santos Julia, Miguel Balbatúa), $22^{\mathrm{a}}$ ed., Vol. 2, México, Siglo XXI, 2003, p. 13. 
retrato que representa al esclavo [...] Bajo la imagen hegeliana del señor, es siempre el esclavo quien se manifiesta. ${ }^{29}$

En Hegel, los factores de señor y siervo dependen de una manera negativa, pues el reconocimiento mutuo posibilita que cada uno de ellos se determine a través del otro, como no-X. Caso similar al del esclavo mencionado por Nietzsche al hablar del pathos reactivo.

Ejemplifiquemos lo anterior: digamos que tenemos un sujeto $\mathrm{A}$, el cual reconoce al otro, esto es a $\mathrm{B}$, haciéndose consciente de sí $y$ viendo que $B$ es un no- $A$; por otro lado tenemos a $B$ que se hace consciente de sí y toma a A como un no-B. En ambos sujetos hay un reconocimiento mutuo caracterizado por un carácter negativo, siendo estos últimos ejemplificaciones burdas de lo pensado por Hegel. En cambio, en Nietzsche, tenemos a un sujeto A, cuyo pathos es de distancia $y$ a un sujeto $B$ cuyo pathos es reactivo. El sujeto $A$, veríamos, se afirma a sí mismo como $\mathrm{A} y$, al presenciar otras fuerzas, es decir a $\mathrm{B}$, no las reconoce como un no-A, sino que sólo marca una diferencia y un contraste libre de negación. El sujeto B, cuyo pathos es reactivo, no se afirma a sí mismo, sino que se afirma a través de A bañándose de la negación característica en el señor y el siervo de Hegel.

Hegel nos dice: «La autoconciencia es en y para sí en cuanto que y porque es en sí y para sí para otra autoconciencia; es decir, sólo es en cuanto se la reconoce $»^{30}$ mostrándonos que para que un sujeto cobre autoconciencia es necesario que éste sea reconocido, y si es necesario que éste sea reconocido, entonces, el sujeto no se afirma a sí mismo, sino que se afirma a través del otro y viceversa. Y sigue:

[...] se presenta fuera de sí [...] en primer lugar, la autoconciencia se ha perdido a sí misma, pues se encuentra como otra esencia; en segundo lugar, con ello ha superado a lo otro, pues no ve tampoco a lo otro como esencia, sino que se ve a sí misma en el otro. ${ }^{31}$

Con lo anterior podremos notar que la esencia o sujeto A, en Hegel, se ve a sí misma en el otro y no se ve a sí misma, en sí y por sí

29 G. Deleuze, op. cit., p. 19.

30 G. W. F. Hegel, La Fenomenología del Espíritu (trad. Wenceslao Roces), Colombia, Fondo de Cultura Económica, 1997, §178, p. 113.

31 Idem., $\$ 179$.

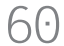


misma. Lo cual nos arrastra nuevamente a la idea de que en Hegel, las esencias se reconocen a través de otras y no a partir de sí mismas como el sujeto cuyo pathos es de distancia en Nietzsche.

En Nietzsche, el esclavo, cuyo pathos es reactivo, reconoce. Prueba de ello es que mediante el otro se afirma; mediante una contraposición cobra existencia. En Hegel, ambas esencias, partícipes de una relación o un conflicto tal como el del señor y el siervo, están fundamentadas en el mutuo reconocimiento que él mismo expresa en su Fenomenología del Espiritu. ${ }^{32}$

Debido a lo anterior, me atrevo a afirmar que el papel de lo negativo no es precisamente uno de los criterios que marcan la diferencia entre los autores, sino el reconocimiento mutuo que los distingue. Pues podemos afirmar, siguiendo el criterio del reconocimiento mutuo, que mientras en uno no está, en el otro sí, y que, además, juega un papel de suma importancia. Consiguiendo que Hegel sea partidario del reconocimiento mutuo, mientras que en Nietzsche este reconocimiento es sólo en una parte: en el pathos reactivo.

Si la dialéctica hegeliana se basa en el mutuo reconocimiento de ambas esencias, y en Nietzsche este reconocimiento no es mutuo, diríamos que, pese a las similitudes de usos de opuestos en ambos autores, Nietzsche no usa propiamente una dialéctica hegeliana.

\section{Otros criterios: finalidad y causalidad}

Presentando diversos criterios a considerar con respecto a las diferencias entre Nietzsche y Hegel con relación a la dialéctica, el siguiente apartado pretende amortiguar lo que parece ser un criterio excluidor. Deleuze nos ha impulsado a una interpretación propia de un solo criterio, diciendo que en la diferencia entre los autores «todo depende del papel de lo negativo en esta relación». ${ }^{33}$ Esto será lo que combatiremos en el presente apartado. Para ello, nos basaremos principalmente en La ciencia jovial o La gaya ciencia de Nietzsche, y en especial, en el aforismo 112 el cual se titula Causa y Efecto.

Primeramente, Nietzsche marca una diferencia entre «explicación» $y$ «descripción» siendo el criterio de diferencia el comprender. "La serie de las "causas" se encuentra en cada caso mucho más comple-

32 Cfr. Ibidem, \$\$178-184, pp. 113-114.

33 G. Deleuze, op. cit., p. 17. 
ta entre nosotros, y así inferimos: esto y lo otro tiene que ir primero, para que le siga aquello; pero con esto no hemos comprendido nada $»_{+}{ }^{34}$ Cuando describimos lo que hacemos es inferir, no comprender, y esto es lo que hacemos mejor según Nietzsche: «Describir es lo que hacemos mejor; explicamos tan poco como nuestros predecesores ${ }_{*}{ }^{35}$

El describir nos posibilita descubrir una múltiple sucesión en donde el 'hombre ingenuo' ve una dualidad entre «causa» $y$ «efecto» ${ }^{36}$ Es decir, este hombre ingenuo ve la dualidad entre causa y efecto como una explicación, siendo que lo único que está haciendo es descubrir una múltiple sucesión de eventos, en otras palabras: describe.

¿Por qué describimos y no explicamos? Nietzsche responde:

¡Cómo habría de ser posible la explicación, si nosotros todo lo transformamos primero en una imagen, en una imagen nuestra! Basta de considerar a la ciencia como la humanización más fiel posible de las cosas, aprendemos a describirnos cada vez más precisamente a nosotros mismos a medida que describimos las cosas y su sucesión. ${ }^{37}$

Al decir que todo lo transformamos primero en imágenes propias, podríamos relacionar lo anterior con el texto de Sobre verdad y mentira en sentido extramoral del mismo autor, donde se plantea la teoría correspondiente a que creamos lenguaje a partir de metáforas teniendo implicaciones tales como creer que sabemos algo de las cosas mismas cuando hablamos de árboles, colores, nieve y flores, cuando lo único que tenemos son metáforas que no corresponden en absoluto a las esencias primitivas de las cosas, haciendo que la «cosa en sí» (la verdad pura) sea totalmente inalcanzable para el creador del lenguaje o de metáforas, conllevando a que las supuestas verdades que tenemos sean meras ilusiones de las que se ha olvidado que son propiamente metáforas de algo inalcanzable ${ }^{38}$

34 F. Nietzsche, La ciencia jovial (trad. José Jara), Barcelona, Monte Ávila Editores: Círculo de lectores, 2002, $§ 112$.

35

Idem.

36 Cfr. Idem.

37 Idem.

38 Cfr. F. Nietzsche, Sobre la verdad y mentira en sentido extramoral, (trad. Luis M. Valdés), Madrid, Tecnos, 1998. 
Teniendo en cuenta la teoría de las metáforas como lenguaje, afirmaríamos que sólo describimos las imágenes, las metáforas, mas no explicamos, en el sentido de que no entendemos la verdad pura o la esencia primitiva. Si no comprendemos, si no explicamos, entonces, el hablar de causas y efectos, involucraría hablar de imágenes, de metáforas que designan una cosa en sí inalcanzable. Por lo que aquellos que ven tal dualidad de causa y efecto, no hacen más que dejarse seducir por un lenguaje caracterizado de ilusiones, imágenes nuestras y metáforas desgastadas:

Un quantum de fuerza es justo un tal quantum de pulsión, de voluntad, de actividad -más aún, no es más que ese mismo pulsionar, ese mismo querer, ese mismo actuar, y, si puede parecer otra cosa, ello se debe tan sólo a la seducción del lenguaje ( $y$ de los errores radicales de la razón petrificados en el lenguaje) el cual entiende y mal entiende que todo hacer está condicionado por un agente, por un «sujeto». ${ }^{39}$

El condicionar un sujeto o un agente a un evento es condicionarle una causa. Al condicionarle una causa, lo único que se hace, siguiendo la teoría del lenguaje de Nietzsche, es querer explicar lo que en realidad nos es imposible, cayendo, así, a una descripción, puesto que la causa y el efecto que se refieran a la cosa en sí como tal es imposible en nuestro lenguaje creado y cargado de seducciones. Por lo anterior, Nietzsche afirma:

Causa y efecto; una dualidad de ese tipo no existe, probablemente, jamás; en verdad, ante nosotros se encuentra una continuidad de la cual aislamos un par de trozos; es de la misma manera en que percibimos un movimiento, siempre y nada más que como puntos aislados, y por consiguiente, en rigor, no lo vemos, sino que lo inducimos. ${ }^{40}$

La anterior cita nos aclara una cuestión de suma importancia. En efecto, en Nietzsche no hay causas y efectos que expresen lo en sí, sino que son metáforas cuyos límites no alcanzan las esencias primitivas de las cosas, pero lo anterior, no quiere decir que nuestro mundo

39 F. Nietzsche, La Genealogía de la Moral, p. 59.

${ }^{40}$ F. Nietzsche, La Ciencia Jovial, $\S 112$. 
se rija por un caos inaprensible, fuera de todo orden, sino que, en una línea, en una secuencia de eventos, elegimos y fragmentamos eventos para así inducir unos de otros. Se niega la reciprocidad de la dicotomía de causa y efecto con la verdad pura o la cosa en sí, pero se acepta la condición inferida o inducida de diversas fragmentaciones propias de una línea secuencial de eventos.

En contraste con lo anterior, tenemos la dialéctica hegeliana, la cual, con lo anteriormente expuesto, nos mostrará un elemento de suma importancia y relevancia para una apropiada distinción entre los autores. En un primer momento mostraremos - con una cita ya expuesta en párrafos anteriores- que la dialéctica usa conceptos para el progreso inmanente de los mismos:

$\mathrm{Al}$ principio motor del concepto [...] yo lo llamo dialéctica [...] Esta Dialéctica negativa puede considerar como su resultado último lo opuesto de una concepción, o decidida la contradicción misma; o también, pobremente, una aproximación a la verdad [...] La más alta Dialéctica del concepto es producir y concebir la determinación -no como oposición y límite simplemente-, sino desde ella, comprender y producir el contenido y el resultado positivos, en cuanto con esto únicamente ella es, desarrollo y progreso inmanente. ${ }^{41}$

Como vemos en la anterior sentencia, la Dialéctica hegeliana trabaja con conceptos en aquel desenvolvimiento o desarrollo inmanente. Pero, ¿̇en qué consisten propiamente estos conceptos?

Las determinaciones, en el desenvolvimiento del concepto, son también, por una parte, conceptos; por otra, ya que el concepto es esencialmente, como Idea, tiene la forma de la existencia y la serie de conceptos que resultan es, por consiguiente, a la vez, una serie de formaciones; así las determinaciones han de considerarse en la ciencia. ${ }^{42}$

De aquí resaltaremos lo siguiente: las determinaciones que propician el desenvolvimiento del desarrollo inmanente en la dialéc-

41 G. W. F. Hegel, Filosofía del Derecho, §31, p. 51; mi énfasis.

42 Ibidem, §32, p. 52; mi énfasis.

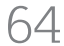


tica son conceptos, estos conceptos o determinaciones existen de tal manera que pueden ser considerados por la ciencia.

Al mencionar la ciencia y las características del concepto, se nos conduce a pensar que el concepto o las concepciones, partícipes en la dialéctica hegeliana, no son metáforas ni ilusiones, ya que si lo fueran, el rigor de la ciencia no los atendería.

De esto obtendríamos como resultado que mientras en Nietzsche las causas y los efectos son ilusiones y una dicotomía inexistente - en el sentido de que no corresponden a la «cosa en sí»-, en Hegel, las causas y los efectos, así como los conceptos, corresponden a una existencia privilegiada no metafórica que se puede tratar con el rigor de la ciencia. En palabras burdas y fulminantes, afirmaríamos que mientras Nietzsche acepta trabajar con metáforas e ilusiones, Hegel trabaja con realidades. Haciendo de esto un criterio de distinción entre ambos autores aún más notable que el expuesto por Deleuze.

Cabe mencionar, por último, una implicación de la concepción de causas y efectos en la obra de Nietzsche. En los Fragmentos póstumos aparece una constante teórica de la que extraemos la siguiente cita:

No tenemos ninguna experiencia en absoluto sobre una causa [...] comprobando psicológicamente, el concepto entero nos llega del convencimiento subjetivo de que nosotros somos causa, es decir, que el brazo se mueve [...] Pero eso es un error [...] buscamos un agente para cada acontecimiento [...] ¿qué hemos hecho? Hemos malentendido como causa un sentimiento de fuerza, de tensión, de resistencia, un sentimiento muscular que es ya el comienzo de la acción [...] Hemos concentrado en el concepto de «causa» nuestro sentimiento de voluntad, nuestro «sentimiento de libertad», nuestro sentimiento de responsabilidad y nuestra intención de hacer algo [...] causa efficiens [eficiente] y finalis [final] son, en la concepción fundamental una única cosa. [...] De una sucesión necesaria de estados no se sigue su relación causal [...] La interpretación de la causalidad es una ilusión [... $]$ No bay causas ni efectos. ${ }^{43}$

Resaltemos la oración que denota la causa eficiente y la final como lo mismo, como causas, las cuales, en su interpretación, radican

43 F. Nietzsche, Fragmentos póstumos (1885-1889), vol. 4, 14[98], (trad. Juan Luis Vermal y Juan Bollinares), España, Tecnos, 2006, pp. 543-544. 
en una ilusión, por lo que no hay causas. Si no hay causas, si no hay causas finales, sino meras ilusiones que no corresponden a la «cosa en sí», podríamos deducir que las relaciones entre fuerzas, en Nietzsche, no tienen una finalidad, no tienen una causa final, por lo que el azar, no goza de un objetivo determinado. En contraste, nuevamente tenemos a Hegel, cuyos conflictos entre sujetos tienen una finalidad, la cual es tener un resultado positivo y en última instancia una finalidad referente al Espíritu Absoluto y a la autoconciencia del mismo. ${ }^{44}$ Logrando un último criterio diferencial, entre los autores, derivado de la mencionada teoría de las metáforas en Nietzsche.

\section{Dicotomías y antagonismos en Nietzsche}

En los apartados I y I.I expusimos que en Nietzsche existen factores de lo negativo a tal grado que acepta eventos antagónicos como lo bueno y lo malo. En el apartado II, mencionamos que estos antagonismos pudieran ser producto de una descripción y no una explicación, logrando que estas negaciones en Nietzsche no fueran más que metáforas e ilusiones.

Cabe aclarar, en este momento, que Nietzsche, en efecto, muestra el carácter de lo negativo a lo largo de su obra como se vio en el apartado I.I, pero él mismo acepta que las negaciones y antagonismos que pudieran parecer dicotomías provenientes de la causa y el efecto son productos de metáforas desgastadas y de meras ilusiones, por lo que reprocharle a Nietzsche el que use aquel lenguaje del que se queja, es ridículo. Ya que él mismo advierte que el problema emerge cuando el sujeto no acepta que trata con metáforas y cree que usa realidades en sí, como lo hace Hegel en el progreso inmanente dialéctico.

\section{Conclusión}

Deleuze propone un criterio de distinción entre Hegel y Nietzsche con relación a la dialéctica, el cual se refiere a lo negativo. Como ambos autores hacen uso de lo negativo, el criterio de Deleuze se vuelve débil. Como refuerzo a la misma argumentación de Deleuze se

${ }^{44}$ Cfr. G. W. F. Hegel, Filosofía del Derecho, §31, p. 51; Fenomenología del Espíritu, p. 120. 
propuso que el criterio de diferencia entre ambos autores no fuera lo negativo, sino el reconocimiento mutuo, ya que éste sólo tiene presencia en la dialéctica hegeliana. En Nietzsche, en el pathos reactivo se tiene un reconocimiento, pero éste no es mutuo, guardando así la distinción entre ambos.

Debido a que Deleuze alude a que sólo hay un criterio general de diferencia entre Hegel y Nietzsche, se presentaron otros argumentos que expresarían que no hay un solo criterio de diferencia sino un conjunto de ellos, en donde, de manera personal, se resaltó la relevancia del criterio correspondiente a la función de las metáforas en Nietzsche en contraposición a la función de los conceptos reales en Hegel.

Como conclusión, diríamos que los comentarios de Deleuze en torno a la dialéctica hegeliana en Nietzsche presentan diversas trabas, las cuales fueron mostradas en el anterior ensayo. 
